\title{
A crise do capital e a relação com a educação brasileira
}

The capital of the crisis and the relationship with brazilian education

\author{
Ivania Maria de Sousa Carvalho Rafael* \\ Instituto Federal de Educação, Ciência e Tecnologia do Ceará \\ Luis Távora Furtado Ribeiro** \\ Universidade Federal do Ceará \\ Maria das Dores Mendes Segundo*** \\ Universidade Estadual do Ceará
}

Resumo Este estudo trata da relação entre a crise do capital e a educação brasileira tendo como objetivo compreender a real função desempenhada pela educação profissional e seus desdobramentos na formação docente, no contexto atual através de um estudo teórico-bibliográfico embasado em autores que dão importância ao tema. Compreende-se a educação como um complexo advindo da categoria trabalho e, por ser também uma das instâncias da sociedade, contribui direta e indiretamente com o capitalismo através da formação de mão de obra para o mercado. Conclui-se que uma educação mesmo nos moldes do capital, pode desenvolver suas aspirações emancipadoras através de intercâmbio de processos de educação mais amplo como a própria vida e os setores que não estão ligados diretamente à educação.

PALAVRAS-ChAVE: Educação; Educação profissional; Crise do capital.

Abstract This study deals with the relationship between the crisis of capital and Brazilian education aiming to understand the real role played by education and its development in teacher education in the current context through a theoretical and bibliographical study grounded in authors that give importance to the issue. Education is understood as a complex arising from the work category and, being also one of the sectors of society, contributes directly and indirectly to capitalism through manpower training for the market. We conclude that an even education in the capital of the mold, can develop their emancipatory aspirations through exchange of broader education processes as life itself and the sectors that are not directly related to education.

KEYWORDS: Education; Professional education; Capital crisis. 


\section{Introdução}

Para falar sobre a crise do capital e a relação com a educação trilharemos a seguir um caminho que começa com a conceituação da crise estrutural do capital à luz de teóricos que estudaram e estudam o assunto, adentrando em conteúdos que tratam da educação nos moldes da crise estrutural do capital.

Tomamos como referência teórica a tese da crise estrutural do capital, defendida por István Mészáros, em sua obra Para Além do Capital, no propósito de compreendermos a real função desempenhada pela educação profissional e seus desdobramentos na formação docente, no contexto atual, sobretudo, no Estado do Ceará, sendo esse o objetivo principal desse estudo.

\section{A crise estrutural do capital}

Para compreendermos como essa crise se apresenta na atualidade utilizamo-nos de uma citação de Mészáros da obra acima citada na qual o autor elenca quatro aspectos que, segundo ele são a "novidade histórica da crise hoje" apresentada sob os aspectos: caráter universal alcance global, escala de tempo e no modo rastejante, ou seja:

1 - seu caráter é universal, em lugar restrito a uma esfera particular (por exemplo, financeira ou comercial, ou afetando este ou aquele ramo particular da produção, aplicando-se a este e não àquele tipo de trabalho, como sua gama específica de habilidades e graus de produtividade, etc.);

2 - seu alcance é verdadeiramente global (no sentido mais literal e ameaçador do termo), em lugar de limitado a um conjunto particular de países (como foram todas as principais crises do passado);

3 - sua escala de tempo é extensa, contínua - se preferir, permanente - em lugar de limitada e cíclica, como foram todas as crises anteriores do capital; 4 - em contraste com as erupções e colapsos mais espetaculares e dramáticos do passado, seu modo de desdobramento poderia ser chamado de rastejante, desde que acrescentemos a ressalva de que nem sequer as convulsões mais veementes ou violentas poderiam ser excluídas no que se refere ao futuro; isto é, quando a complexa maquinaria agora ativamente engajada na "administração da crise" e no "deslocamento" mais ou menos temporário das crescentes contradições perder sua força. (MÉSZÁROS, p. 795-796, 2011).

Uma das maneiras práticas e bastante simples de entender a atual crise do capital é observar cuidadosamente ao nosso redor e procurar em meio a todas as instâncias a interferência dessa crise na economia, no emprego, na educação, na política, na saúde e demais complexos sociais. Se assim o fizermos cuidadosamente, enxergaremos a realidade em que estamos vivendo e que o teórico Mészáros considera ser uma crise estrutural do capital porque:

Em termos simples e gerais, uma crise estrutural afeta a totalidade de um complexo social em todas as relações com suas partes cons- 
tituintes ou subcomplexos, como também a outros complexos aos quais é articulada. Diferentemente, uma crise não estrutural afeta apenas algumas partes do complexo em questão, e assim, não importa o grau de severidade em relação às partes afetadas, não pode por em risco a sobrevivência contínua da estrutura global. (MÉSZAROS, 2011, p. 797).

$\mathrm{O}$ autor busca deixar clara a diferença entre os momentos de crise vivenciados pelo mundo capitalista e compara a crise estrutural com a crise não estrutural de maneira que o leitor compreenda que estamos vivenciando uma crise que atinge todos os complexos, ela é globalizada, generalizada.

Neste tipo de conjuntura, não há como transferir o problema para outro complexo com a finalidade de superar determinada dificuldade tendo em vista que o conflito já alcançou outros níveis, não é possível deslocar a crise. Nas palavras de Mészáros "[...] o deslocamento das contradições só é possível enquanto a crise for parcial, relativa e interiormente manejável pelo sistema, demandando apenas mudanças - mesmo que importantes - no inteiro do próprio sistema relativamente autônomo" (MÉSZAROS, 2011, p. 797). Diante de uma crise global, os diversos complexos são atingidos.

Outro destaque é também a presença do capital humano ainda nos dias atuais, porque a sociedade também culpa o indivíduo pela sua não inserção exitosa no mercado de trabalho, instigando-o a competitividade, é preciso provar o tempo todo não apenas que somos bons, mas que somos melhores que os outros. $\mathrm{O}$ capital humano tão presente no modelo de produção fordista agora cede espaço para a empregabilidade, que conforme Freres:

O termo empregabilidade possui uma trajetória que percorreu todo o século XX, chegando até o século XXI. A origem desse termo está relacionada à problemática do emprego/desemprego, constituindo-se como uma categoria muito utilizada no mercado de trabalho e nos meios educacionais. Sua lógica, atualmente, refere-se à responsabilização do indivíduo por um problema que é gerado na materialidade das relações sociais que subordina o trabalho e as atividades humanas dele decorrentes ao jugo do capital. (FRERES, 2008, p. 62).

Mais adiante, Freres (2008) ressalta a importância do conceito empregabilidade na consolidação do neoliberalismo ao ser disseminado através da Organização de Cooperação e de Desenvolvimento Econômicos (OCDE), a Organização Internacional do Trabalho (OIT), a Organização das Nações Unidas (ONU) e a União Europeia (EU) (FRERES, 2008, p. 65/66). A empregabilidade tem um grau elevado de significância no toyotismo ${ }^{1}$. A inserção no mercado de trabalho é o que dá retorno financeiro ao trabalhador, a empregabilidade é uma possibilidade muitas vezes presente na abstração, mas que é vista como uma realidade que gera a competitividade entre os trabalhadores. $\mathrm{O}$ termo utilizado para designar uma possibilidade e não uma condição real de emprego nos leva a corroborar com Ciavatta e Frigotto quando dizem:

As palavras ou vocábulos que usamos para nomear as coisas ou os fatos e acontecimentos não são inocentes. Buscam dar sentido ou 
significar estas coisas, estes fatos ou estes acontecimentos em consonância com interesses vinculados a determinados grupos, classes ou frações de classe. (GAUDÊNCIO FRIGOTTO; MARIA CIAVATTA, 2003, p. 46).

Outro agravante é quando o trabalhador não se vê em um posto de trabalho ou em uma profissão que não lhe garanta bons salários, nesse caso somos levados a pensar que a culpa é exclusivamente nossa. Gentilli (2002, p. 52) ressalta que a escola se configura como um espaço de interesse em que se desenvolve a integração do indivíduo ao mercado de trabalho de maneira que desperta nos educandos essa esperança, porém o que não se enfatiza nesses discursos é que nem todos chegarão ao posto de trabalho almejado. A impossibilidade de gozar dos benefícios da integração da educação não está no aluno em si, mas nos poucos postos de trabalho existentes, o que gera consequentemente, mais competitividade entre os educandos e entre os profissionais.

Essa integração em que a escola é a promotora tem por missão a

[...] difusão e socialização dos conhecimentos e saberes, a escola, afirmavam os teóricos deste campo, contribui para formar o capital humano que, como um poderoso fator produtivo, permite um aumento tendencial das rendas individuais e, consequentemente, o crescimento econômico das sociedades. (GENTILLI, 2002, p. 53).

O tão aclamado capital humano que a escola forma para o mercado do trabalho é visto na sociedade atual sob o viés da empregabilidade, na qual o indivíduo se torna responsável não apenas pelo seu sucesso ou insucesso, mas principalmente pela sua inserção no mercado de trabalho, deixando de lado o contexto histórico, social e econômico.

A dificuldade de manter-se no mercado de trabalho e, em alguns momentos, de inserir-se nesse mercado, deve-se principalmente a crise pela qual passa a economia mundial. A crise estrutural que assola a economia mundial deixa suas consequências em todas as instâncias da sociedade, atingindo mais diretamente e de maneira mais cruel na população pobre e nos trabalhadores assalariados de maneira geral. Em crises menores, a saída era encontrada dentro do próprio sistema promovendo abertura do consumo e consequentemente o escoamento da produção e a geração de renda para supressão da crise, ou seja,

[...] em primeiro lugar, são superadas com sucesso as limitações imediatas de cada uma, graças à interação entre elas. (Por exemplo, a barreira imediata para a produção é positivamente superada pela expansão do consumo e vice-versa.) Assim, os limites parecem verdadeiramente ser meras barreiras a serem transcendidas, e as contradições imediatas não são apenas deslocadas, mas diretamente utilizadas como alavancas para o aumento exponencial no poder aparentemente ilimitado de autopropulsão do capital. (MẼSZÁROS, 2011, p. 798).

O exemplo dado por Mészáros explicita sem ser simplista o entendimento dessa relação entre as várias crises e nos coloca de frente com a questão de modo a entendermos que o momento de crise estrutural em que vivemos não dá condições de criar mecanismos que possam transcender ou deslocar essas contradições internas que levam a superação do conflito. 
As crises são benéficas ao capitalismo porque são neste período que surgem as explorações mais efetivas através das altas taxas e ao mesmo tempo empréstimos com juros altos, demissões com admissões por salários mais baixos, dentre outras ações que farão com que o capitalismo atinja os seus objetivos. Freitas (1999, p. 120) adverte que "Procura-se colocar como referência a própria 'ausência de referência', caracterizando a incerteza como única verdade e fazendo-se uma assepsia das relações sociais presentes na prática social" (FREITAS, 1999 p. 120). Através das incertezas cogitamse possibilidades de superação da crise e desta forma uma crise se sobressai à outra, o que não é possível em uma crise estrutural.

Introduzindo-se um pouco na história da crise estrutural do capital, temos como início o período pós-crise de 1930 em que o mundo buscava se recuperar e que se arrastou até a década de 1970, com o trabalho ainda sob a organização taylorista/ fordista ${ }^{2}$, momento em que surge o período chamado de "Estado de Bem-Estar". Para Saviani esse momento representou:

[...] um determinado grau de compromisso entre Estado, empresas e sindicatos de trabalhadores que, numa fase de crescimento da economia, assegurou um relativo equilíbrio social e impulsionou significativamente o desenvolvimento das forças produtivas capitalistas, cujo resultado se materializou num avanço tecnológico de tal proporção que deu origem a uma nova 'revolução industrial': a revolução microeletrônica, também denominada 'revolução da informática' ou 'revolução da automação'. (SAVIANI, p. 21).

Destarte, estávamos diante de uma nova realidade em que a rapidez com que a produção se desenvolvia exigia do trabalhador uma constante transformação para acompanhar o rápido desenvolvimento da tecnologia e, em contrapartida, com máquinas mais autônomas e inteligentes teríamos mais tempo livre para o trabalhador dedicar-se a atividades intelectuais, pessoais, científicas e artísticas. Contudo, nos deparamos com o oposto, cada vez mais o trabalhador se envolve com mais e mais trabalho, aperfeiçoamento, concorrência entre os trabalhadores e a exigência constante de melhoria para continuar no mercado.

Saviani (2002) enfatiza que o padrão produtivo que até então era taylorista/ fordista sofre alterações que o transformaram em um novo tipo de produção chamado de toyotismo ou acumulação flexível como também é conhecido, como nova forma de superar a crise do capitalismo em que os mecanismos de controle vão do estado ou sindicato para as empresas. Neste sistema o sindicato passa a ser uma construção dentro da própria empresa o que deixa o trabalhador cada vez mais dependente e vinculado às ideologias do capitalismo e às exigências do patrão.

Neste modelo econômico de produção prevalece a qualidade total que corresponde à lógica da produção destrutiva, ou como diz Antunes (1999, p. 50): "na empresa da era da reestruturação produtiva, torna-se evidente que quanto mais "qualidade total' os produtos devem ter, menor deve ser seu tempo de duração". Isso possibilita ao capitalismo um giro maior na produção tendo em vista que gera o consumismo exacerbado que tenta dessa forma superar as crises. 
Essa crise estrutural afeta diretamente a educação, tendo em vista a compreensão que temos em que a educação se caracteriza como um complexo advindo do trabalho e por ser também uma das instâncias da sociedade que de maneira direta e indireta contribui para com o capitalismo através da formação de mão de obra para o mercado de trabalho. Corroboramos com Mészáros (2008, p. 25) quando diz que "Poucos negariam hoje que os processos educacionais e os processos sociais mais abrangentes de reprodução estão intimamente ligados". O que não significa dizer que mudaríamos toda a sociedade mudando apenas a educação. É preciso mudança em todo o quadro social e econômico, não apenas no quadro educacional. $\mathrm{O}$ mesmo autor enfatiza que "[...] é necessário romper com a lógica do capital se quisermos contemplar a criação de uma alternativa educacional significativamente diferente." (id., p. 27)

Asseveramos que a educação institucionalizada alimenta, em boa medida os interesses do capital. Mészáros destaca que:

A educação institucionalizada, especialmente nos últimos 150 anos, serviu - no seu todo - ao propósito de não só fornecer os conhecimentos e o pessoal necessário à máquina produtiva em expansão do sistema do capital, como também gerar e transmitir um quadro de valores que legitima os interesses dominantes, como se não pudesse haver nenhuma alternativa à gestão da sociedade, seja na forma "internalizada" (isto é, pelos indivíduos devidamente "educados" e aceitos) ou através de uma dominação estrutural e uma subordinação hierárquica e implacavelmente impostas. (id., p. 35 grifo do autor).

A ordem natural, supostamente inalterada que compõe o discurso e as práticas na sociedade vigente é em boa medida, transmitida à educação e inculcada na cabeça dos estudantes como imutável. Como compreendemos, não há neutralidade científica. Dessa forma, não há como negar a intenção velada nos discursos contidos nas políticas educacionais, que tendem a oferecer a educação como um remédio para todos os males e principalmente como a chave que abre as portas que aprisionam o sistema econômico capitalista.

Percebemos, no entanto, que a crise estrutural que assola o capitalismo mundial está atacando implacavelmente todas as instâncias da sociedade e impregnando o sistema educacional. Assim como em outras crises, está utilizando da educação como meio não somente de abastecer o capital com mão de obra barata e precarizada, mas principalmente como um instrumento de fertilização do discurso da empregabilidade tão difundido pelo toyotismo.

\section{A educação nos moldes da crise estrutural do capital}

O capitalismo ${ }^{3}$ é um sistema econômico, um modo de produção no qual a produção e a distribuição desses produtos são de propriedade privada obedecendo a lógica do capital. A educação da atualidade está voltada aos interesses do capital enquanto a formação humana está presente na maioria das vezes, apenas no papel. Vêse que na hora da prática o ensino vislumbra a aplicabilidade, o consumo e o retorno financeiro acima de tudo, especialmente na educação profissional. Esquece-se que por trás daquele aluno que busca aprender está um ser humano e ele deseja muito mais que 
uma profissão, ele deseja inserção na sociedade. Notadamente na educação profissional é marcante a ideologia empresarial e capitalista no estudo de determinada profissão, prepara-se o estudante inclusive para o empreendedorismo, uma vez que já é previsível que não haja lugar para todos no mercado de trabalho.

Buscamos deixar claro neste estudo que a educação profissional não pode ser vista e utilizada como uma máquina de produzir pessoas produtivas para abastecer o capitalismo. Ressaltamos que a perspectiva de uma educação tendo como base o desenvolvimento tecnológico ou uma educação que desenvolva realmente a potencialidade intelectual dos alunos é suprimida por uma educação que está diretamente voltada para atender às exigências do mercado. Segundo Saviani (2002, p. 22), "É, com efeito, aquilo que poderíamos chamar de "concepção produtivista de educação" que domina o panorama educativo da segunda metade do século XX". É a educação a serviço da produtividade, em que a formação da mão de obra é o principal direcionamento da atividade educativa, principalmente do currículo escolar.

A produção e o consumo são fatores importantes para alimentar o capitalismo, como consequência, é comum nos depararmos com o discurso que mais produção é sinônimo de mais socialização dos produtos. Sabemos que não é uma verdade e entendemos que o problema não reside na baixa produção de bens na sociedade capitalista, mas como diz Frigotto (1995, p. 175), deve-se, "[...] sobretudo aos mecanismos sociais que impedem a socialização desta produção". De maneira mais generalizada é comum aprendermos desde cedo que é preciso produzir mais e mais para que todos tenham acesso a essa produção, mas, a verdade é que esse discurso de mais produção está incutido no desenvolvimento de mais consumo para que aqueles que já são, sozinhos donos de quase tudo, não dividam que possuem com os outros.

No atual contexto da crise estrutural a educação de maneira geral também sofre suas pressões e se enquadra na dificuldade de existir em meio aos interesses capitalistas que, em sua maioria toma a cena nas escolas. Diante dessa realidade é preciso procurarmos meios de desenvolver "[...] processos educativos não imediatistas que concorram para a formação omnilateral e, portanto, para os processos de emancipação humana, a busca do sentido 'radical' de escola unitária, no plano do conhecimento e no plano político-organizativo, é fundamental” (FRIGOTTO, 1995, p. 176). Apesar de estarmos tratando da educação na modalidade profissional temos a consciência que este acontecimento não é uma realidade apenas dessa modalidade de ensino, enfatizamos o ensino profissional tendo em vista que é desse tipo de ensino que se buscam o profissional que irá atender ao mercado cada vez mais exigente e precarizado, que exige do trabalhador múltiplos conhecimentos.

Uma característica presente na educação profissional nos dias atuais é a polivalência, termo empregado para qualificar o trabalhador como aquele que está apto a desempenhar várias funções em nome de um aumento na produção e, consequentemente o consumo, continuando assim o ciclo do capital. Algumas vezes, o termo polivalência é utilizado como sinônimo de politecnia, como se esta palavra tivesse o mesmo significado de polivalência, em favor do capitalismo. Uma formação que faz do estudante um ser capaz de desempenhar várias funções em um ambiente em prol 
do desenvolvimento econômico e não em prol do desenvolvimento humano como é o sentido originário do termo politecnia, o contrário disso só é possível em uma sociedade adversa a nossa, ou seja, no socialismo. Para Rodrigues (1998, p. 117), a politecnia tem por objetivo "impedir o equívoco de se entender que a formação politécnica seria o caminho 'natural' demandado pelo modo de produção capitalista."

Desse modo compreendemos que é preciso ir além de uma formação de mão de obra, é preciso buscar a formação omnilateral ${ }^{4}$, tendo como meta a necessidade de transformação na educação como um todo.

Em se tratando das escolas profissionais do Estado do Ceará, a dualidade existente historicamente está teoricamente superada, é proposta uma "radicalização do dualismo" a proposta de uma escola integral que busca a valorização do aluno e do futuro profissional. Porém o que conjecturamos diante de uma leitura nas entrelinhas do próprio Manual Operacional da Tese - documento norteador da filosofia de gestão empresarial empregado nas Escolas Estaduais de Educação Profissional do Estado do Ceará - EEEP's, é que prevalece como mais decisivo para o projeto educacional a formação do aluno como futuro profissional. Frigotto $(1995$, p. 188) reforça esse pensamento e explicita que "A base da argumentação passa pelo ideário da teoria do capital humano, atualizada pelas 'teses' da sociedade do conhecimento e da 'qualidade total”.

No campo da formação de professores o ideário da busca pela qualidade total, competitividade e resultados na produção também é reforçado. Os professores das escolas profissionais do estado do Ceará com funcionamento em tempo integral de trabalho se veem na obrigação de buscar incessantemente novos conhecimentos e novos rumos para a sua efetiva promoção nessa concepção educacional em que é preciso mostrar cotidianamente quem se destaca diante dos demais. Isso também se faz necessário principalmente para os professores com vínculos temporários que precisam mostrar serviço para terem seus contratos renovados.

Não somos contra a busca por mais e melhores profissionalizações dos professores, só não corroboramos com a pressão por essa melhora quando não se oferecem condições propícias nas mesmas proporções nem tampouco uma estabilidade para os professores que são contratados por tempo determinado. A luta não deve se deter apenas às dificuldades diárias na escola, ela se estende por ampliações de direitos dentro e fora da escola que possam promover a capacitação docente e a seguridade do trabalho.

Gentilli (2002) chama a atenção para uma questão da transformação do capital humano nos dias atuais. Ele destaca que "[...] a Teoria do Capital Humano, principal enquadramento teórico usado para definir o sentido da relação trabalho-educação no capitalismo contemporâneo, também mudou para pior." Frigotto (2002, p. 71) também chama a atenção para essas novas características assumidas pela educação a "[...] ideologia da globalização e, de outro, a perspectiva mistificadora da reestruturação produtiva embasam, no campo educativo, a nova vulgata da pedagogia das competências e a promessa da empregabilidade". Estas nomenclaturas buscam dizer mais uma vez e de forma diferenciada que "os excluídos de que eles são os culpados por sua exclusão". 
A educação nos moldes do capital atende aos anseios da produção e do consumo, consequentemente, a formação docente nesses moldes tende a reproduzir os interesses capitalistas na relação professor-aluno, todavia, o que resguardamos é uma formação docente que vai contra essa concepção, embasada criticamente e que desenvolva uma prática que leve ao desenvolvimento da criticidade nos educandos. Como diz Mészáros (2008, p. 47), "Romper com a lógica do capital na área da educação equivale, portanto, a substituir as formas onipresentes e profundamente enraizadas de internalização mistificadora por uma alternativa concreta abrangente" (grifo do autor) é romper com a estrutura da naturalização das desigualdades e com o discurso da meritocracia.

Tendo em vista que a criticidade dos educandos não se configura como um ponto importante para o Estado capitalista, uma vez que, um povo culto não é necessariamente o objetivo do modo de produção capitalista, largamente representado pelo poder público, que de algum modo, não deseja ampliar os gastos com a qualificação da educação e da formação docente.

Todavia, o capital em crise, dentro dos seus limites, passa a se interessar pela formação docente, para que o professor desenvolva nos alunos competências adequadas ao mercado de trabalho. Isso aconteceu principalmente com a mudança de produção do capital do taylorismo/fordismo para o toyotismo. A formação docente é desejável à medida que ela contribui para a produção capitalista, para Saviani (2002, p. 22)

[...] os dispêndios com educação passaram a ser considerados desejáveis, não apenas por razões sociais ou culturais, mas especificamente por motivos econômicos, e transformam-se num investimento de retorno ainda mais compensador do que outros tipos de investimento ligados à produção material. (SAVIANI, 2002, p. 22).

Por conseguinte, a educação desenvolveria em si um valor que gera rentabilidade e lucro e não mais como um bem de consumo próprio. Contextualizamos a educação como parte da estrutura social que, reconfigurada nos moldes da crise estrutural, inevitavelmente carregará em seus ombros o peso de ser um instrumento de libertação do indivíduo. Mas não é ela sozinha que vai alcançar essa libertação almejada. Mészáros (2008, p. 45 grifo do autor) chama a atenção para enxergamos que "[...] fica bastante claro que a educação formal não é a força ideologicamente primária que consolida o sistema do capital; tampouco ela é capaz de, por si só, fornecer uma alternativa emancipadora radical". Faz-se necessário destacarmos aqui a importância que o autor dá aos termos "primária" e "por si só", entendemos nesse destaque que a educação pode promover discussões, despertar para questões de assumir posições críticas diante das adversidades do capital, mas ele deixa claro que não será apenas a educação unicamente capaz de fazer a transformação sozinha.

Dando relevância ao fato de a educação contribuir com a transformação da sociedade, o autor nos revela a possibilidade de, através da educação, alcançarmos o patamar de esclarecedora, de fonte instrutora e informante da situação de opressão vigente ao mesmo tempo em que instiga o educando a tomar uma posição diante dos acontecimentos de injustiça e desigualdade social. Porém, a educação sozinha nunca 
solucionará essa desigualdade dentro de uma sociedade capitalista. Freres (2008, p. 119) nos alerta de que:

[...] os teóricos da educação que se afinam com a lógica empresarial - de que a educação é a mola-mestra do desenvolvimento econômico e da redução das desigualdades sociais - contribuem para que o capital continue como sistema vigente. Suas teorias desenvolvidas acerca da educação não passam de um falseamento da realidade, visto que a educação está inserida numa totalidade social, totalidade essa regida pela lógica do capital que se sustenta da miséria humana. Assim sendo, como parte dessa totalidade, a educação jamais - ela não possui em si o potencial revolucionário, embora seja imprescindível no processo de transformação social - resolverá as desigualdades existentes (FRERES, 2008, p. 119).

A educação tem o seu papel na transformação social. Através dela alcançaremos degraus possíveis na construção de uma nova sociedade, porém esta nova sociedade há de acontecer quando a mudança ocupar um nível estrutural, global e que se mudem principalmente as relações com o capital.

\section{Conclusão}

Sabemos, no entanto, que a educação sozinha não fará a transformação social, porque isso não é possível com a educação a serviço do capital. Na circunstância em que está é muito mais fácil manter o consenso do que alcançar uma emancipação tendo em vista que não é essa a intenção da sociedade capitalista.

Como foi discutido anteriormente, não devemos esperar que a educação institucionalizada realize a mudança, que leve a uma conscientização política, social e econômica da sociedade. O que devemos ter em mente é que apesar de ser um veículo de informação, a escola especialmente não é o único meio de discussão de ideias e projetos que alavanque a mudança esperada, existem outros meios, dos quais podemos destacar os sindicatos e os movimentos independentes do setor governamental, "pois muito do nosso processo contínuo de aprendizagem se situa, felizmente, fora das instituições educacionais formais" (MÉSZÁROS, 2008, p. 53).

Contudo, uma educação, mesmo nos moldes do capital, pode desenvolver suas aspirações emancipadoras através de intercâmbio de processos de educação mais amplo como a própria vida e os demais setores que não estão ligados diretamente à educação.

Dessa forma, é possível sonhar com uma educação diferente que forma para uma emancipação vindoura, que não corresponde a uma transformação no tempo presente com o modelo de economia capitalista, ou seja, a possibilidade em uma outra sociedade. 


\section{Referências}

ANTUNES, R. Adeus ao Trabalho? Ensaio sobre as Metamorfoses e a Centralidade do Mundo do Trabalho. São Paulo: Cortez/Unicamp, 1999.

Século XXI: nova era da precarização estrutural do trabalho? Seminário Nacional de Saúde Mental e Trabalho - São Paulo, 28 e 29 de novembro de 2008.

Os sentidos do Trabalho: Ensaio sobre a afirmação e a negação do trabalho. $2^{\mathrm{a}}$ ed. São Paulo, SP: Boitempo, 2009.

FREITAS, L. C. de. Crítica da Organização do Trabalho Pedagógico e da Didática. Campinas: Papirus. 1995. FRERES, H. A. F.; RABELO, J.; MENDES SEGUNDO, M. D. O papel da educação na sociedade capitalista: Uma análise onto-histórica. Disponível em: <http://www. sbhe.org.br/novo/congressos/cbhe5/pdf/932.pdf〉. Acesso em: 11 de ago. 2014.

FRERES, H.de A. Educação e a Ideologia da Empregabilidade: Formando para o (Des)Emprego. Dissertação de Mestrado - Universidade Federal do Ceará. Fortaleza, 2008.

FRIGOTTO, G.; CIAVATTA, M.; RAMOS, M. Ensino médio integrado: concepções e contradições. 2005.

A política de educação profissional no governo Lula: um percurso histórico controvertido. Educ. Soc., Campinas, vol. 26, n. 92, p. 1087-1113, Especial - Out. 2005. Disponível em <http://www.cedes.unicamp.br>. Acesso em: 3 maio 2012.

FRIGOTTO, G. Educação e Trabalho: bases para debater a Educação Profissional emancipadora. Perspectiva, Florianópolis, v. 19, n. 1, p. 71-87, jan./jun. 2001.

Globalização e Crise do Emprego: Mistificações e Perspectivas da Formação Técnico-Profissional. Pesquisado em: <http://www.senac.br/BTS/252/boltec252c.htm>. Acesso em: 15 jun. 2012.

A relação da educação profissional com a universalização da educação básica. In: MOLL, J.; Colab. Educação profissional e tecnologia no Brasil contemporâneo, Artmed Editora S.A: São Paulo, 2010.

Educação e a crise do capitalismo real. São Paulo: Cortez, 1995.

FRIGOTTO, G.; CIAVATTA, M. Educar o trabalhador cidadão produtivo ou o ser humano emancipado? Revista Trabalho, Educação e Saúde. v. 1, n. 1, Rio de Janeiro, p. 45-60, 2003.

GENTILI, P. Três teses sobre relação trabalho e educação em tempos neoliberais. In: LOMBARDI, J. C.; SAVIANI, D.; SANFELICE, J. L. (Orgs.). Capitalismo, Trabalho e Educação. Campinas: Autores Associados. 2002.

MÉSZÁROS, I. Para além do capital: rumo a uma teoria da transição. Trad. Paulo Cezar Castanheira, Sérgio Lessa. - 1.ed. revista. - São Paulo: Boitempo, 2011.

A educação para além do capital. 2. ${ }^{\text {a }}$ ed. São Paulo: Boitempo, 2008.

RODRIGUES, J. A educação politécnica no Brasil. Niterói: Editora UFF, 1998.

SAVIANI, D. Transformações do capitalismo, do mundo do trabalho e da educação. In: LOMBARDI, JC; SAVIANI, D.; SANFELICE, J. L. (Orgs.). Capitalismo, Trabalho e Educação. Campinas, SP: Autores Associados, HISTEDBR, 2002.

. Da Nova LDB ao FUNDEB: por uma outra política educacional. 3. ed. Autores Associados: Campinas, 2008.

Formação de professores: aspectos históricos e teóricos do problema no contexto brasileiro. Rev. Bras. Educ. [online]. 2009, vol.14, n. 40, p. 143-155. 
SAVIANI, D. História das ideias pedagógicas no Brasil. 3a ed. Campinas, Autores Associados, 2010. (Memória da educação). In: SAVIANI, D. Pedagogia Histórico-Crítica: primeiras aproximações. Campinas/SP: Autores Associados, 2012.

\section{Notas}

${ }^{1}$ Segundo BRITO e FRANÇA (2010), o Toyotismo pode ser compreendido como o modelo de organização do trabalho, originário da fabrica Toyota, no Japão, que se expandiu pelo mundo capitalista no processo de reestruturação produtiva.

${ }^{2}$ Segundo Ricardo Antunes é o modo de produção presente na indústria ao longo do século XX, baseado na “[...] produção em massa de mercadorias, que se estruturava a partir de uma produção mais homogeneizada e enormemente verticalizada" (2009, p. 38).

${ }^{3} \mathrm{O}$ Capitalismo teve inicio na Europa. As suas características aparecem desde idade média (do século XI ao $\mathrm{XV}$ ) com a transferência do centro da vida econômica social e política dos feudos para a cidade. Disponível em: <http://www.sohistoria.com.br/ef2/capitalismo/>. Acesso em: 10 de setembro 2014.

${ }^{4}$ Para Manacorda a omnilateralidade é "a chegada histórica do homem a uma totalidade de capacidades produtivas e, ao mesmo tempo, a uma totalidade de capacidades de consumo e prazeres, em que se deve considerar sobretudo o gozo daqueles bens espirituais, além dos materiais, e dos quais o trabalhador tem estado excluído em consequência da divisão do trabalho" (MANACORDA, 2007, p. 89).

* Técnica em Assuntos Educacionais no Instituto Federal de Educação, Ciência e Tecnologia do Ceará, Crato, Ceará, Brasil.

** Professor doutor da Universidade Federal do Ceará, Fortaleza, Ceará, Brasil.

*** Professora doutora da Universidade Estadual do Ceará, Fortaleza, Ceará, Brasil.

\section{Correspondência}

Ivania Maria de Sousa Carvalho Rafael - Instituto Federal do Ceará - Campus Crato. Rodovia CE 292, S/N., Km 05, 63100000 - Crato, Ceará - Brasil.

E-mail: ivanyacarvalho@yahoo.com.br - luistavora@uol.com.br - mariadores.segundo@uece.br

Recebido em 24 de agosto de 2015

Aprovado em 23 de março de 2016 